\title{
STRATEGI PEMASARAN PADA PELATIHAN PUBLIC SPEAKING QUECARD SUKABUMI
}

\author{
Dicki Prayudi \\ AMIK BSI SUKABUMI \\ Jl. Cemerlang No. 8, Sukakarya, Sukabumi \\ e-mail: dicki.dcd@bsi.ac.id
}

\begin{abstract}
Abstraksi
QueCard adalah nama lembaga pelatihan yang fokus kepada pengembangan soft skill terutama dalam bidang komunikasi di Sukabumi. Tujuan didirikannya lembaga ini adalah untuk memberikan pilihan dan kemudahan bagi peserta dalam mengembangkan komunikasinya. Kelas Public Speaking adalah kelas yang ditujukan kepada mahasiswa atau pekerja yang memerlukan pelatihan komunikasi untuk menunjang kebutuhan pekerjaan ataupun kepentingan pribadinya. Peneliti dilakukan dengan pendekatan secara langsung kepada informan untuk mengamati perilaku, pendapat, sikap serta tanggapan informan terkait dengan subjek penelitian. Penelitian menggunakan parameter tunggal yang menjadi parameter studi yaitu STP (Segmenting, Targeting, dan Positioning). Bauran pemasarannya berdasarkan yang dikemukakan oleh Kotler untuk pemasaran jasa yaitu: Product, Place, Price, Promotion, Process, Physical Evidence, dan People. Pada penelitian ini, metode kualitatif diambil sebagai metode yang akan digunakan peneliti dalam merumuskan skema penelitian lebih lanjut. Berdasarkan analisis lingkungan internal pemasaran QueCard Public Speaking yang diformulasikan pada matrik IFAS, pemasaran QueCard Public Speaking masih memiliki kekuatan yang lebih besar dibandingkan kelemahan. Hasil matrik tersebut menghasilkan hasil pembobotan QueCard Public Speaking yang mempunyai skor 2,05 untuk kekuatan pemasaran dan 0,85 untuk hasil pembobotan kelemahan pemasaran QueCard Public Speaking. Hasil 2,90 yaitu hasil pembobotan kekuatan ditambah dengan kelemahan.
\end{abstract}

Kata Kunci: Rancangan, Pemasaran, Analisis SWOT

\begin{abstract}
QueCard is the name of the training institute that focuses on the development of soft skills, especially in the field of communications in Sukabumi. The objective of establishing the institute is to provide choice and convenience for the participants to develop communication. Research also approaches descriptive analysis to interpret the data obtained with the fact that being in the field so as to get a research subjects. Research using a single parameter into parameter studies are STP (Segmenting, Targeting, and Positioning). Its marketing mix based on that proposed by Kotler's marketing services, such as: Product, Place, Price, Promotion, Process, Physical Evidence, and People. Researchers conducted a detailed elaboration in order to provide data and information for this study. Based on the analysis of the external environment of marketing QueCard Public Speaking at the point where the position is that the overall result of 2.95 is 1.75 and the point opportunities results threat there is a difference of 1.20 to 0.55 . It is concluded that the external environment of marketing QueCard Public Speaking is above the average of point that have more opportunities than threats.
\end{abstract}

Keyword: Marketing, SWOT Analyst, Public Speaking

Diterima Februari 10, 2018; Revisi Februari 16 , 2018; Disetujui Maret 15, 2018 
JURNAL SWABUMI, Vol.6 No.2 September 2018, pp. 174 183

ISSN: 2355-990X

E-ISSN: 2549-5178

1. Pendahuluan

Dunia

menumbuhkan

perkembangan yang sangat pesat di berbagai perusahaan manufaktur, perdagangan, keuangan dan jasa pelayanan, dengan perbedaan hukum dan struktur organisasi yang luas. Namun ada satu persamaan, yaitu komitmen akan tujuan perusahaan dengan menciptakan nilai ekonomi untuk mengembalikan sumber daya yang digunakan dan untuk mendapatkan laba atau keuntungan yang maksimal secara terus-menerus. Banyak hal yang menjadi pertimbangan untuk melakukan strategi memajukan organisasi atau entitas perusahaan, dimulai dengan bussines plan yang kuat, permodalan yang kuat, aspek legalitas yang kuat sampai ke penyerapan sumber daya manusia yang maksimal. Salah satu poin yang diharapkan perusahaan atau lembaga lain dalam penyerapan sumber daya manusia tersebut adalah memiliki kemampuan yang sesuai, cakap dan diharapkan dapat membantu permasalahanpermasalahan yang dihadapi oleh organisasi.

Keahlian berbicara di depan umum maupun keahlian-keahlian lain yang serupa dan berkaitan di Indonesia masih belum diterima luas sebagai suatu keahlian yang bergengsi bagi individu maupun institusi. Ini berbeda dengan negara-negara seperti Amerika Serikat atau Singapura, di mana kemahiran berbicara mendapat tempat yang terhormat sebagai suatu keahlian. Padahal tidak sedikit waktu dipergunakan manusia untuk berbicara di depan umum, utamanya dalam konteks karir dan profesionalitas kerja. (Wahyuni, 2015) menyambapkan bahwa berkomunikasi dengan orang lain merupakan situasi yang hampir terjadi di seluruh proses kehidupan. Komunikasi menentukans kualitas kehidupan manusia, dan memiliki kemampuan berkomunikasi yang efektif sangatlah diperlukan, untuk menyampaikan ide, gagasan dan pengetahuan kepada masyarakat.

Identifikasi masalah yang diidentifikasi dalam penelitian ini antara lain faktor internal dan eksternal yang mempengaruhi peningkatan jumlah peserta, alternatif strategi apa saja yang dapat diterapkan dalam meningkatkan jumlah peserta dan program apa saja yang dapat diterapkan dalam meningkatkan jumlah peserta.

\section{Metode Penelitian}

Peneliti melakukan pendekatan secara langsung kepada informan untuk mengamati perilaku, pendapat, sikap serta tanggapan informan terkait dengan subjek penelitian. Peneliti juga melakukan pendekatan descriptive analysis untuk menginterprestasikan data yang diperoleh dengan fakta yang berada di lapangan sehingga mendapatkan gambaran yang jelas tentang subjek penelitian. Dengan demikian, peneliti akan menggambarkan fakta-fakta keadaan dari objek pebelitian yang ada dan menganalisis kebenaran fakta tersebut dari data yang diperoleh. Peneliti melakukan survei, wawancara serta observasi dan mendokumentasikan data untuk mengambil data-data yang diperlukan dalam penelitian. Peneliti juga menyebarkan kuesioner kepada peserta pelatihan dan subjek-subjek pemberi data agar informasi yang didapat valid dan susuai dengan sasaran.

Penelitian menggunakan parameter tunggal yang menjadi parameter studi yaitu STP (Segmenting, Targeting, dan Positioning). Menurut (Lita, 2010) Bauran pemasarannya untuk pemasaran jasa yaitu: Product, Place, Price, Promotion, Process, Physical Evidence, dan People. Peneliti melakukan penjabaran secara rinci agar dapat memberikan masukan data dan informasi untuk penelitian ini. Pada penelitian ini, metode kualitatif diambil sebagai metode yang akan digunakan peneliti dalam merumuskan skema penelitian lebih lanjut. Berbagai aspek diambil datanya agar dapat merumuskan tujuan penelitian di Quecard Public Speaking. Dimulai dari aspek kajian sampai kepada pengambilan data dari peserta pelatihan, QueCard Management, dan dokumen yang ada di dalam lembaga.Sumber data penelitian adalah

\section{Hasil dan Pembahasan}

Sejak didirikan pada tahun 2016, QueCard Public Speaking telah memiliki tiga batch dengan jumlah peserta sekitar 30 peserta individual untuk kelas Take. Selain itu, pihak manajemen juga telah melakukan kerja sama dengan beberapa sekolah dan kampus untuk melakukan seminar dan pelatihan secara Away ke sekolah atau kampus tersebut. Bentuk kerja sama adalah dengan memberikan pelatihan, pembicara 
atau sharing untuk meraka yang akan menjalalani masa sidang agar dapat mempersiapkannya dengan maksimal.

Peserta yang berasal dari lembaga, perusahaan maupun instansi, biasanya pengelolaan pelatihan komunikasi diberikan kepada kantor pusat masing-masing lembaga. Hal ini dapat diantisipasi dengan mendatangkan lembaga serupa di kota sendiri untuk efisiensi maupun penghematan data.

Terdapat beberapa program yang dapat menjadi positioning serta menghambat terjadinya persaingan secara kuat pada pelatihan komunikasi ini, diantaranya adalah dengan melakukan konsep kerja sama, event, serta WOM. Pengelola lembaga melakukan kerja sama secara intensif dengan lenbaga pengajaran, sekolah, kampus, instansi, perusahaan-perusahaan, untuk memperkenalkan lembaga serta menjalin ikatan erat dengan stake holder untuk membangun kebersamaan. Selain itu, pengelola juga mengadakan event setiap sebulan sekali untuk memperkenalkan lembaga kepada umum secara berkala dan menarik. Konsep WOM juga menjadi daya tarik tersendiri untuk pengelola memperkenalkan QueCard Public Speaking kepada masyarakat sesuai dengan target dan sasaran pasar lembaga.

\subsection{Analisis Data}

Analisis data dilakukan apabila data sudah terkumpul dan akan dilakukan analisis. Peneliti melakukan analisis melalui data primer dan sekunder. Peneliti melakukan analisis dengan menggunakan analisis
SWOT yaitu instrumen yang dilakukan untuk melakukan analisis strategi. Empat hal yang akan dianalisis yaitu sejumlah kekuatan (strength) dan kelemahan (weakness) dari sisi internal, dan faktor peluang (opportunities) dan ancaman (threats) dari sisi eksternal.

Tahapan ini akan menyimpulkan informasi dari penjelasan dan uraian visi, misi, tujuan, kebijakan QueCard Public Speaking yang diperlukan untuk menganalisis dan merumuskan strategi pembangunan pemasaran QueCard Public Speaking dengan menggunakan alat IFAS Matrix, EFAS Matrix, Matrix Internal Eksternal (IE), SWOT Matrix, dan QSPM (Arnawa et al., 2017). Tahapan sebelum menganalisis lingkungan eksternal, peneliti melakukan scanning lingkungan eksternal, setelah itu memilih indikator kunci untuk dibobotkan di EFAS.

\subsection{Analisis Lingkungan Eksternal Pemasaran \\ Analisis lingkungan eksternal} pemasaran dari lembaga merupakan cara untuk mengetahui faktor-faktor di luar kendali perusahaan yang dapat memberikan pengaruh pada kinerja perusahaan. Keberhasilan perusahaan terletak pada kemampuannya mengadaptasi dan beradaptasi dalam lingkungan yang selalu berubah, hal ini mempengaruhi strategi perusahaan untuk menentukan bagaimana cara serta kapan saat yang tepat untuk bertahan dan berkembang. Berikut adalah hasil scanning lingkungan eksternal:

Tabel 1. Tabel Analisis Lingkungan Eksternal Pemasaran

\begin{tabular}{|c|c|c|c|c|}
\hline \multirow[b]{2}{*}{ Faktor } & \multirow[b]{2}{*}{ Indikator } & \multicolumn{3}{|c|}{ Checklist } \\
\hline & & $\begin{array}{c}\text { Indikator } \\
\text { Kunci }\end{array}$ & Peluang & Ancaman \\
\hline \multirow{2}{*}{ Demografi } & Kepadatan penduduk meningkat & & $\sqrt{ }$ & \\
\hline & Jumlah usia produktif terbanyak & $\sqrt{ }$ & $\sqrt{ }$ & \\
\hline \multirow{3}{*}{ Geografi } & Suhu alam yang sejuk & & $\sqrt{ }$ & \\
\hline & $\begin{array}{l}\text { Kota transisi yang diapit oleh kota } \\
\text { kota besar }\end{array}$ & & & $\sqrt{ }$ \\
\hline & Lokasi berada di pusat kota & $\sqrt{ }$ & $\sqrt{ }$ & \\
\hline \multirow{4}{*}{ Ekonomi } & $\begin{array}{l}\text { Grafik nilai IPM yang stabil } \\
\text { cenderung meningkat positif }\end{array}$ & & $\sqrt{ }$ & \\
\hline & Masyarakat cenderung konsumtif & $\sqrt{ }$ & $\sqrt{ }$ & \\
\hline & $\begin{array}{l}\text { Pendapatan masyarakat mayoritas } \\
\text { berpenghasilan menengah }\end{array}$ & & & $\sqrt{ }$ \\
\hline & $\begin{array}{l}\text { Golongan pengeluaran per kapita } \\
\text { berada di tingkat menengah }\end{array}$ & & & $\sqrt{ }$ \\
\hline
\end{tabular}




\begin{tabular}{|c|c|c|c|c|}
\hline \multirow{3}{*}{ Pendidikan } & $\begin{array}{l}\text { Jumlah kampus perguruan tinggi } \\
\text { meningkat }\end{array}$ & & $\sqrt{ }$ & \\
\hline & Jumlah mahasiswa aktif meningkat & $\sqrt{ }$ & $\sqrt{ }$ & \\
\hline & Jumlah kampus semakin banyak & & $\sqrt{ }$ & \\
\hline \multirow{2}{*}{ Politik } & $\begin{array}{l}\text { UU pengaturan tentang legalitas } \\
\text { kursus }\end{array}$ & & $\sqrt{ }$ & \\
\hline & $\begin{array}{l}\text { UU dukungan pemerintah tentang } \\
\text { pendidikan nonformal }\end{array}$ & $\sqrt{ }$ & $\sqrt{ }$ & \\
\hline \multirow[b]{2}{*}{ Teknologi } & $\begin{array}{l}\text { Teknologi internet memudahkan } \\
\text { mempelajari public speaking }\end{array}$ & & $\sqrt{ }$ & \\
\hline & $\begin{array}{l}\text { Teknologi untuk mendukung } \\
\text { presentasi yang semakin } \\
\text { berkembang }\end{array}$ & $\sqrt{ }$ & $\sqrt{ }$ & \\
\hline \multirow{3}{*}{$\begin{array}{l}\text { Pemasok } \\
\text { Pengajar }\end{array}$} & $\begin{array}{l}\text { Physical Icon dari radio masih } \\
\text { dipercaya masyarakat }\end{array}$ & & $\sqrt{ }$ & \\
\hline & $\begin{array}{l}\text { Banyaknya masyarakat yang } \\
\text { mendengarkan radio }\end{array}$ & & $\sqrt{ }$ & \\
\hline & $\begin{array}{l}\text { Banyak calon public speaker yang } \\
\text { ingin freelance mengajar }\end{array}$ & $\sqrt{ }$ & $\sqrt{ }$ & \\
\hline \multirow[t]{3}{*}{ Pesaing } & $\begin{array}{l}\text { Belum ada pesaing yang fokus } \\
\text { membuat lembaga di Kota } \\
\text { Sukabumi }\end{array}$ & $\sqrt{ }$ & $\sqrt{ }$ & \\
\hline & Pesaing kuat berada di luar kota & & & $\sqrt{ }$ \\
\hline & Program pesaing lebih matang & & & $\sqrt{ }$ \\
\hline \multirow{2}{*}{ Konsumen } & $\begin{array}{l}\text { Konsumen pelatihan public } \\
\text { speaking beragam background }\end{array}$ & & $\sqrt{ }$ & \\
\hline & $\begin{array}{l}\text { Konsumen semakin membutuhkan } \\
\text { pelatihan public speaking }\end{array}$ & $\sqrt{ }$ & $\sqrt{ }$ & \\
\hline
\end{tabular}

Dari beberapa data termasuk data hasil wawancara EFAS kepada owner dan Stakeholder, peneliti mempertimbangkan dan menganalisa semua data dengan pembobotan pembaruan sebagai berikut:

Tabel 2. Tabel EFAS Matrik Analisis Lingkungan Eksternal Pemasaran

\begin{tabular}{|c|c|c|c|c|}
\hline Faktor & Indikator & Bobot & Rating & $\begin{array}{l}\text { Skor } \\
\text { Bobot }\end{array}$ \\
\hline \multicolumn{5}{|c|}{ Peluang } \\
\hline Demografi & Jumlah usia produktif terbanyak & 0,10 & 3 & 0,30 \\
\hline Geografi & Lokasi berada di pusat kota & 0,05 & 2 & 0,10 \\
\hline Pendidikan & Jumlah mahasiswa aktif meningkat & 0,10 & 3 & 0,30 \\
\hline Politik & $\begin{array}{l}\text { UU dukungan pemerintah tentang pendidikan } \\
\text { nonformal }\end{array}$ & 0,05 & 1 & 0,05 \\
\hline Teknologi & $\begin{array}{l}\text { Teknologi untuk mendukung presentasi yang } \\
\text { semakin berkembang }\end{array}$ & 0,05 & 2 & 0,10 \\
\hline Pesaing & $\begin{array}{l}\text { Belum ada pesaing yang fokus membuat } \\
\text { lembaga di Kota Sukabumi }\end{array}$ & 0,10 & 3 & 0,30 \\
\hline Konsumen & $\begin{array}{l}\text { Konsumen semakin membutuhkan pelatihan } \\
\text { public speaking }\end{array}$ & 0,15 & 4 & 0,60 \\
\hline & Jumlah & 0,60 & 1, & \\
\hline \multicolumn{5}{|c|}{ Ancaman } \\
\hline Ekonomi & $\begin{array}{l}\text { Pendapatan masyarakat mayoritas } \\
\text { berpenghasilan menengah }\end{array}$ & 0,05 & 2 & 0,10 \\
\hline
\end{tabular}




\begin{tabular}{|l|l|c|c|c|} 
Pesaing & Program pesaing lebih matang & 0,05 & 1 & 0,05 \\
\hline $\begin{array}{l}\text { Pemasok } \\
\text { Pengajar }\end{array}$ & Mentor yang berkualitas sulit dicari & 0,15 & 4 & 0,60 \\
\hline Geografi & Kota transisi yang diapit oleh kota kota besar & 0,05 & 1 & 0,05 \\
\hline Pendidikan & Pemahaman Public Speaking kurang & 0,10 & 4 & 0,40 \\
\hline \multicolumn{2}{c}{ Jumlah } & 0,40 & & 1,05 \\
\hline \multicolumn{2}{c}{ Total } & $\mathbf{1 , 0 0}$ & & $\mathbf{2 , 9 5}$ \\
\hline
\end{tabular}

Berdasarkan analisis lingkungan eksternal pemasaran QueCard Public Speaking dimana posisinya berada di titik 2,95 yaitu hasil keseluruhan pembobotan peluang adalah 1,75 dan hasil pembobotan ancaman sebesar 1,20 terdapat selisih 0,55. Hal ini menyimpulkan bahwa lingkungan eksternal pemasaran QueCard Public Speaking berada diatas rata-rata yaitu memiliki poin peluang lebih banyak dari pada ancaman. Faktor yang paling besar yaitu pada peluang konsumen yang membutuhkan pelatihan public speaking, oleh karena itu pengelola QueCard Public Speaking harus dapat memanfaatkan peluang tersebut, dan dapat, memperkenalkan QueCard lebih luas.

Eksternal Strategic Factors Analysis Summary (EFAS) matrix adalah cara untuk mengevaluasi faktor eksternal di QueCard Public Speaking yang akan menganalisis peluang yang perlu dimanfaatkan, serta kelemahan yang harus dihindari berdasarkan unsur-unsur dari demografi, geografi, pendidikan, politik, ekonomi, dan sosial. Hasil rangkuman analisis dari unsur tersebut digunakan untuk memberikan pembobotan terhadap unsur-unsur indikator yang akan dihitung terhadap pemasaran QueCard Public Speaking.

\subsection{Analisis Lingkungan Internal Pemasaran QueCard \\ Langkah selanjutnya yang dilakukan adalah melakukan analisis untuk faktor peluang dan ancaman pada lembaga. Analisis ini menggunakan matrik Internal Strategic Factors Analysis Summary (IFAS) yang akan menilai kekuatan yang dimiliki serta kelemahan yang harus dihindari sebagai modal dasar dalam keunggulan bersaing ataupun kepuasan peserta berdasarkan faktor sumber daya manusia, manajemen, keuangan, serta operasional.}

Tabel 3. Tabel Analisis Lingkungan Internal Pemasaran

\begin{tabular}{|c|c|c|c|c|c|}
\hline Faktor & Dimensi & Interpretasi & Kekuatan & Kelemahan & $\begin{array}{c}\text { Indikator } \\
\text { Kunci }\end{array}$ \\
\hline \multirow{7}{*}{ Product } & \multirow{3}{*}{ Materi } & $\begin{array}{l}\text { Materi disesuaikan } \\
\text { dengan kebutuhan }\end{array}$ & $\sqrt{ }$ & & $\sqrt{ }$ \\
\hline & & $\begin{array}{l}\text { Materi lengkap } \\
\text { dengan praktek dan } \\
\text { games }\end{array}$ & $\sqrt{ }$ & & \\
\hline & & $\begin{array}{l}\text { Materi belum bisa } \\
\text { diakses via online }\end{array}$ & & $\sqrt{ }$ & \\
\hline & \multirow[b]{2}{*}{ Pendaftaran } & $\begin{array}{l}\text { Bebas biaya } \\
\text { pendaftaran }\end{array}$ & $\sqrt{ }$ & & \\
\hline & & $\begin{array}{l}\text { Pendaftaran } \\
\text { dipermudah dengan } \\
\text { hanya mengisi form }\end{array}$ & $\sqrt{ }$ & & \\
\hline & $\begin{array}{l}\text { Program } \\
\text { Pembelajaran }\end{array}$ & $\begin{array}{l}\text { Tersedia kelas Take } \\
\text { dan Away untuk } \\
\text { dipilih peserta }\end{array}$ & $\sqrt{ }$ & & \\
\hline & $\begin{array}{l}\text { Lama } \\
\text { pembelajaran }\end{array}$ & $\begin{array}{l}2 \text { Bulan per level } \\
\text { untuk kelas Take dan }\end{array}$ & $\sqrt{ }$ & & $\sqrt{ }$ \\
\hline
\end{tabular}




\begin{tabular}{|l|l|l|l|l|} 
& $\begin{array}{l}\text { disesuaikan untuk } \\
\text { kelas Away }\end{array}$ & & \\
\cline { 2 - 5 } $\begin{array}{l}\text { Durasi } \\
\text { pembelajaran }\end{array}$ & $\begin{array}{l}\text { Pembelajaran } \\
\text { maksimal 3 jam per } \\
\text { pertemuan dianggap } \\
\text { cukup }\end{array}$ & $\sqrt{ }$ & & \\
\hline Permodalan & $\begin{array}{l}\text { Kurangnya modal } \\
\text { untuk } \\
\text { mengembangkan } \\
\text { usaha }\end{array}$ & & $\checkmark$ & \\
\hline Penilaian & $\begin{array}{l}\text { Pemberian nilai } \\
\text { dilakukan dengan } \\
\text { transparan }\end{array}$ & $\sqrt{ }$ & & \\
\hline \multirow{2}{*}{$\begin{array}{l}\text { Ujian dan } \\
\text { Sertifikat belum } \\
\text { mempunyai nama } \\
\text { yang terkenal }\end{array}$} & $\begin{array}{l}\text { Sertifikat diberikan } \\
\text { setiap level }\end{array}$ & $\sqrt{ }$ & & \\
\hline
\end{tabular}

\begin{tabular}{|c|c|c|c|c|c|}
\hline \multirow{4}{*}{ Price } & $\begin{array}{l}\text { Biaya } \\
\text { pendaftaran }\end{array}$ & $\begin{array}{l}\text { Bebas biaya } \\
\text { pendaftaran }\end{array}$ & $\sqrt{ }$ & & \\
\hline & $\begin{array}{l}\text { Biaya } \\
\text { bulanan }\end{array}$ & $\begin{array}{l}\text { Biaya bulanan sangat } \\
\text { terjangkau }\end{array}$ & $\sqrt{ }$ & & $\sqrt{ }$ \\
\hline & Biaya ujian & $\begin{array}{l}\text { bebas biaya ujian } \\
\text { hanya ada biaya } \\
\text { sertifikat }\end{array}$ & $\sqrt{ }$ & & \\
\hline & Biaya lain & $\begin{array}{l}\text { Tidak ada biaya } \\
\text { lainnya }\end{array}$ & $\sqrt{ }$ & & \\
\hline \multirow{7}{*}{ People } & \multirow{3}{*}{ Mentor } & $\begin{array}{l}\text { Mentor } \\
\text { berpengalaman } \\
\text { sebagai public } \\
\text { speaker }\end{array}$ & $\sqrt{ }$ & & \\
\hline & & $\begin{array}{l}\text { Sulit mencari mentor } \\
\text { baru yang berkualitas }\end{array}$ & & $\sqrt{ }$ & $\sqrt{ }$ \\
\hline & & $\begin{array}{l}\text { Waktu mengajar } \\
\text { mentor yang terbatas }\end{array}$ & & $\sqrt{ }$ & \\
\hline & \multirow[b]{2}{*}{ Pengelola } & $\begin{array}{l}\text { Pengelola tidak full } \\
\text { mengurusi } \\
\text { manajemen }\end{array}$ & & $\sqrt{ }$ & \\
\hline & & $\begin{array}{l}\text { Pengelola } \\
\text { menggunakan } \\
\text { aplikasi jarak jauh } \\
\text { untuk merumuskan } \\
\text { strategi }\end{array}$ & & $\sqrt{ }$ & \\
\hline & $\begin{array}{l}\text { Penjaga } \\
\text { Studio }\end{array}$ & $\begin{array}{l}\text { Penjaga jarang } \\
\text { berada di tempat }\end{array}$ & & $\sqrt{ }$ & \\
\hline & Physical Icon & $\begin{array}{l}\text { Physical icon telah } \\
\text { dikenal masyarakat }\end{array}$ & $\sqrt{ }$ & & $\sqrt{ }$ \\
\hline \multirow{4}{*}{ Place } & \multirow{3}{*}{$\begin{array}{l}\text { Lokasi } \\
\text { tempat }\end{array}$} & $\begin{array}{l}\text { Lokasi tempat } \\
\text { strategis, berada di } \\
\text { pusat kota }\end{array}$ & $\sqrt{ }$ & & $\sqrt{ }$ \\
\hline & & $\begin{array}{l}\text { Lokasi terjangkau } \\
\text { angkutan umum }\end{array}$ & $\sqrt{ }$ & & \\
\hline & & $\begin{array}{l}\text { Belum terdapat plang } \\
\text { di lokasi }\end{array}$ & & $\sqrt{ }$ & \\
\hline & $\begin{array}{l}\text { Kenyamanan } \\
\text { tempat }\end{array}$ & $\begin{array}{l}\text { Suasana sepi tidak } \\
\text { banyak gangguan }\end{array}$ & $\sqrt{ }$ & & $\sqrt{ }$ \\
\hline
\end{tabular}




\begin{tabular}{|c|c|c|c|c|c|}
\hline \multirow{8}{*}{$\begin{array}{l}\text { Physical } \\
\text { Evidence }\end{array}$} & \multirow{2}{*}{$\begin{array}{l}\text { Ruang } \\
\text { pelatihan }\end{array}$} & $\begin{array}{l}\text { Ruangan sedikit } \\
\text { sempit karena } \\
\text { terdapat alat music }\end{array}$ & & $\sqrt{ }$ & \\
\hline & & $\begin{array}{l}\text { Tidak tersedia kursi } \\
\text { dan meja pelatihan }\end{array}$ & & $\sqrt{ }$ & $\sqrt{ }$ \\
\hline & $\begin{array}{l}\text { Ruang } \\
\text { tunggu }\end{array}$ & $\begin{array}{l}\text { Ruang tunggu } \\
\text { terdapat di outdoor }\end{array}$ & $\sqrt{ }$ & & \\
\hline & Toilet & $\begin{array}{l}\text { Toilet tersedia } \\
\text { dengan baik }\end{array}$ & $\sqrt{ }$ & & \\
\hline & Mushola & $\begin{array}{l}\text { Tidak terdapat } \\
\text { mushola, ruang kelas } \\
\text { sering dijadikan } \\
\text { tempat beribadah }\end{array}$ & & $\sqrt{ }$ & \\
\hline & \multirow[b]{2}{*}{ Area parkir } & Area parkir luas & $\sqrt{ }$ & & \\
\hline & & $\begin{array}{l}\text { Penerangan gelap } \\
\text { apabila malam hari }\end{array}$ & & $\sqrt{ }$ & \\
\hline & Fasilitas lain & $\begin{array}{l}\text { Tersedia wifi, AC dan } \\
\text { ruangan ganti }\end{array}$ & $\sqrt{ }$ & & $\sqrt{ }$ \\
\hline \multirow{4}{*}{ Process } & Prosedur & $\begin{array}{l}\text { Prosedur pengajaran } \\
\text { mudah dan tidak } \\
\text { rumit }\end{array}$ & $\sqrt{ }$ & & $\sqrt{ }$ \\
\hline & \multirow[t]{2}{*}{$\begin{array}{l}\text { Jadwal } \\
\text { belajar }\end{array}$} & $\begin{array}{l}\text { Jadwal kelas Take } \\
\text { ditentukan } \\
\text { manajemen, } \\
\text { sehingga sering } \\
\text { berbenturan }\end{array}$ & $\sqrt{ }$ & & \\
\hline & & $\begin{array}{l}\text { Jadwal kelas Away } \\
\text { menyesuaikan } \\
\text { peserta }\end{array}$ & $\sqrt{ }$ & & $\sqrt{ }$ \\
\hline & Mekanisme & $\begin{array}{l}\text { Mekanisme } \\
\text { pembelajaran belum } \\
\text { paten dan dibuat } \\
\text { secara tertulis }\end{array}$ & & $\sqrt{ }$ & \\
\hline \multirow{8}{*}{ Promotion } & Iklan & $\begin{array}{l}\text { Tidak memasang } \\
\text { iklan karena } \\
\text { keterbatasan dana }\end{array}$ & & $\sqrt{ }$ & $\sqrt{ }$ \\
\hline & $\begin{array}{l}\text { Personal } \\
\text { selling }\end{array}$ & $\begin{array}{l}\text { Dana yang terbatas } \\
\text { sehingga tidak } \\
\text { melakukan personal } \\
\text { selling }\end{array}$ & & $\sqrt{ }$ & \\
\hline & $\begin{array}{l}\text { Sales } \\
\text { promotion }\end{array}$ & $\begin{array}{l}\text { Sales promotion } \\
\text { hanya dilakukan via } \\
\text { medsos prabadi }\end{array}$ & $\sqrt{ }$ & $\sqrt{ }$ & \\
\hline & $\begin{array}{l}\text { Public } \\
\text { relation }\end{array}$ & $\begin{array}{l}\text { Tidak tersedia sdm } \\
\text { untuk public relation }\end{array}$ & & $\sqrt{ }$ & \\
\hline & WOM & $\begin{array}{l}\text { WOM menjadi alat } \\
\text { utama untuk promosi }\end{array}$ & $\sqrt{ }$ & & \\
\hline & Media sosial & $\begin{array}{l}\text { Memiliki account } \\
\text { twitter sendiri dengan } \\
\text { jumlah follower } \\
\text { banyak }\end{array}$ & $\sqrt{ }$ & & $\sqrt{ }$ \\
\hline & Media fisik & $\begin{array}{l}\text { Belum memasang } \\
\text { media fisik karena } \\
\text { keterbatasan dana }\end{array}$ & & $\sqrt{ }$ & \\
\hline & $\begin{array}{l}\text { Diskusi } \\
\text { panel }\end{array}$ & $\begin{array}{l}\text { Menerjunkan } \\
\text { pengelola mengikuti } \\
\text { diskusi panel }\end{array}$ & $\sqrt{ }$ & & \\
\hline
\end{tabular}


Dari hasil scanning lingkungan internal pemasaran QueCard Public Speaking maka dapat disimpulkan strategi sementara yang akan diambil dari cara pembobotan indikator kunci. Peneliti melakukan wawancara dengan owner QueCard Public Speaking dan peserta pelatihan yang akan memberikan pengaruh terhadap faktor internal dalam pemasaran lembaga.

\begin{tabular}{|c|c|c|c|c|c|}
\hline \multicolumn{2}{|c|}{ Faktor } & Indikator & Bobot & Rating & $\begin{array}{l}\text { Skor } \\
\text { Bobot }\end{array}$ \\
\hline \multicolumn{6}{|c|}{ Kekuatan } \\
\hline \multirow[b]{3}{*}{ Product } & Materi & $\begin{array}{l}\text { Materi disesuaikan dengan } \\
\text { kebutuhan }\end{array}$ & 0,05 & 3 & 0,15 \\
\hline & Pendaftaran & Bebas biaya pendaftaran & 0,05 & 2 & 0,10 \\
\hline & $\begin{array}{l}\text { Lama } \\
\text { Pembelajaran }\end{array}$ & $\begin{array}{l}2 \text { Bulan per level untuk kelas } \\
\text { Take dan disesuaikan untuk } \\
\text { kelas Away }\end{array}$ & 0,05 & 2 & 0,10 \\
\hline Price & $\begin{array}{l}\text { Biaya } \\
\text { bulanan }\end{array}$ & $\begin{array}{l}\text { Biaya bulanan sangat } \\
\text { terjangkau }\end{array}$ & 0,05 & 3 & 0,15 \\
\hline People & Physical Icon & $\begin{array}{l}\text { Physical icon telah dikenal } \\
\text { masyarakat }\end{array}$ & 0,10 & 4 & 0,40 \\
\hline \multirow[b]{2}{*}{ Place } & $\begin{array}{l}\text { Lokasi } \\
\text { tempat }\end{array}$ & $\begin{array}{l}\text { Lokasi tempat strategis, } \\
\text { berada di pusat kota }\end{array}$ & 0,10 & 4 & 0,40 \\
\hline & $\begin{array}{l}\text { Kenyamanan } \\
\text { tempat }\end{array}$ & $\begin{array}{l}\text { Suasana sepi tidak banyak } \\
\text { gangguan }\end{array}$ & 0,05 & 1 & 0,05 \\
\hline $\begin{array}{l}\text { Physical } \\
\text { evidence }\end{array}$ & Fasilitas lain & $\begin{array}{l}\text { Tersedia wifi, } A C \text { dan } \\
\text { ruangan ganti }\end{array}$ & 0,10 & 3 & 0,30 \\
\hline Process & $\begin{array}{l}\text { Jadwal } \\
\text { belajar }\end{array}$ & $\begin{array}{l}\text { Jadwal kelas Away } \\
\text { menyesuaikan peserta }\end{array}$ & 0,05 & 2 & 0,10 \\
\hline Promotion & Media sosial & $\begin{array}{l}\text { Memiliki account twitter } \\
\text { sendiri dengan jumlah } \\
\text { follower banyak }\end{array}$ & 0,10 & 3 & 0,30 \\
\hline \multicolumn{3}{|c|}{ Jumlah } & 0,70 & \multicolumn{2}{|c|}{2,05} \\
\hline \multicolumn{6}{|c|}{ Kelemahan } \\
\hline Product & $\begin{array}{l}\text { Ujian dan } \\
\text { sertifikat }\end{array}$ & $\begin{array}{l}\text { Sertifikat belum mempunyai } \\
\text { nama yang terkenal }\end{array}$ & 0,05 & 1 & 0,05 \\
\hline People & Mentor & $\begin{array}{l}\text { Sulit mencari mentor baru } \\
\text { yang berkualitas }\end{array}$ & 0,10 & 4 & 0,40 \\
\hline $\begin{array}{l}\text { Physical } \\
\text { evidence }\end{array}$ & $\begin{array}{l}\text { Ruang } \\
\text { pelatihan }\end{array}$ & $\begin{array}{l}\text { Tidak tersedia kursi dan meja } \\
\text { pelatihan }\end{array}$ & 0,05 & 2 & 0,10 \\
\hline Promotion & Iklan & $\begin{array}{l}\text { Tidak memasang iklan } \\
\text { karena keterbatasan dana }\end{array}$ & 0,05 & 3 & 0,15 \\
\hline Place & $\begin{array}{l}\text { Lokasi } \\
\text { tempat }\end{array}$ & $\begin{array}{l}\text { Belum terdapat plang di } \\
\text { lokasi }\end{array}$ & 0,05 & 3 & 0,15 \\
\hline \multicolumn{3}{|c|}{ Jumlah } & 0,30 & \multicolumn{2}{|c|}{0,85} \\
\hline \multicolumn{3}{|c|}{ Total } & 1,00 & & 2,90 \\
\hline
\end{tabular}

Berdasarkan analisis lingkungan internal pemasaran QueCard Public Speaking yang diformulasikan pada matrik IFAS, pemasaran QueCard Public Speaking masih memiliki kekuatan yang lebih besar dibandingkan kelemahan. Hasil matrik tersebut menghasilkan hasil pembobotan QueCard Public Speaking yang mempunyai skor 2,05 untuk kekuatan pemasaran dan 0,85 untuk hasil pembobotan kelemahan pemasaran QueCard Public Speaking. Hasil 2,90 yaitu hasil pembobotan kekuatan 
ditambah dengan kelemahan. Keunggulan QueCard Public Speaking berada pada faktor physical icon yang telah dikenal oleh masyarakat, lokasi tempat strategis yang berada di tengah kota, dan fasilitas lengkap tersedia AC, wi-fi dan ruang ganti. Sementara kelemahan yang harus segera diperbaiki adalah dari faktor People yaitu lembaga kesulitan mencari mentor lain yang berkualitas.

\subsection{Analisis Strategi Pasar}

Segmentasi Pasar pada lembaga ini adalah bertujuan untuk mengidentifikasi variable segmentasi dan segmentasi pasar serta mengembangkan pembentuk segmen yang menguntungkan. Sesuai dengan lingkungn eksternal yang telah di rinci, segmentasi lembaga pelatihan Public Speaking pada QueCard manajement ini adalah mahasiswa aktif di Kota Sukabumi yang berusia dari 18-30 tahun. Sesuai dengan peluang yang telah dipetakan, interval usia tersebut adalah masa-masa usia pekerja atau mahasiswa aktif yang memerlukan pelatihan lain atau penambahan ilmu komunikasi lebih baik dan terarah untuk bekal di kemudian hari.

Positioning dari lembaga pelatihan QueCard Public Speaking adalah turunan ilmu komunikasi public speaking, yaitu lebih kepada ilmu komunikasi tata bicara, presentasi serta pemahamannya. Semua materi yang diberikan disesuaikan untuk menggali pemahaman siswa tentang public speaking. Diharapkan setelah mempelajari, siswa dapat mengaplikasikannya di dunia keseharian dan kerja, terutama untuk berkomunikasi satu arah, presentasi serta keberanian untuk berbicara di depan umum.

\subsection{Analisis SWOT Pemasaran}

Matriks Internal Eksternal dikembangkan dari model General Electric (GE-Model). Parameter yang digunakan meliputi kekuatan yang dimiliki perusahaan dan pengaruh eksternal yang dihadapi. Tujuan penggunaan model ini adalah untuk memperoleh strategi bisnis di tingkat yang lebih tinggi.

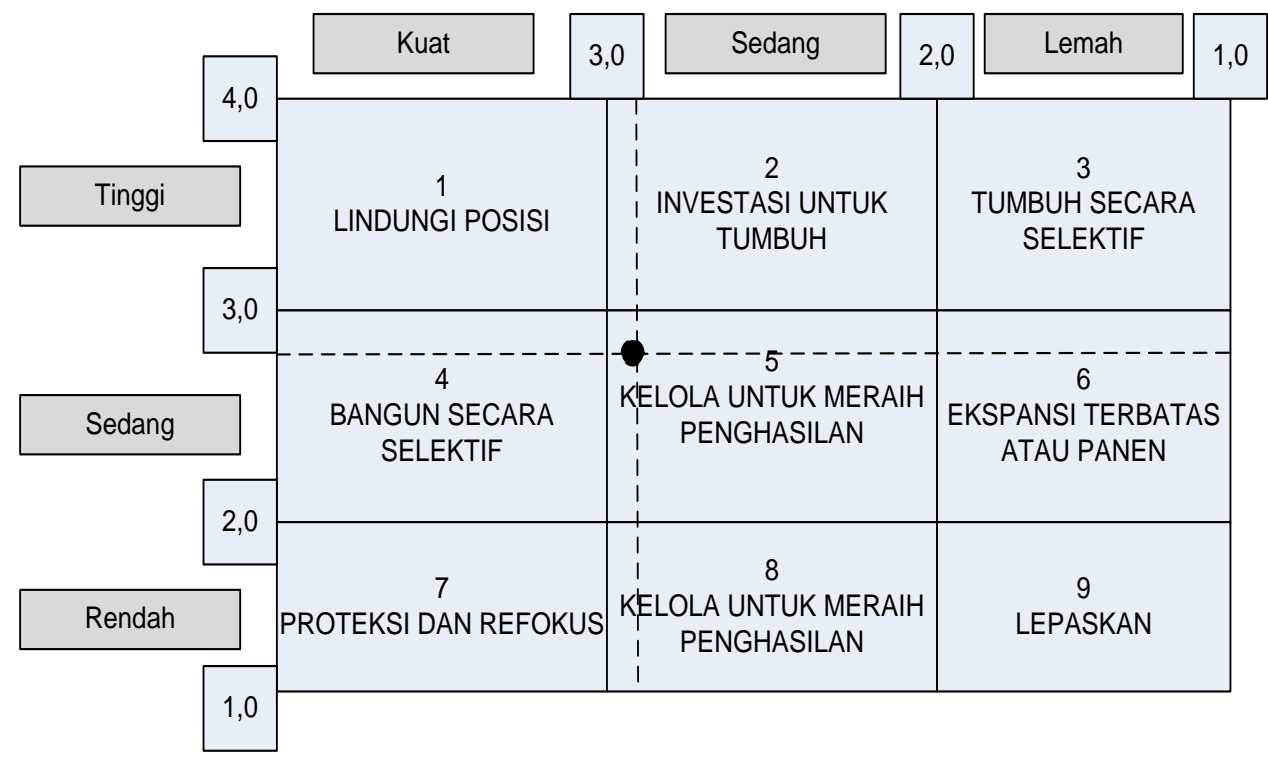

Gambar 2. Matrik Analisis Internal Eksternal Pemasaran

Matrik Internal Eksternal diatas dapat dilihat bahwa posisi pemasaran QueCard Public Speaking berada pada posisi stabilitas, maka pemasaran QueCard Public Speaking berkonsentrasi melalui sel pengelolaan untuk meraih penghasilan (sedang dan sedang) yaitu membuat proyeksi untuk melindungi program yang ada, serta memfokuskan investasi pada segmen-segmen dimana profitabilitasnya baik dan beresiko relatif rendah. Sumber dan data dari matriks IFAS, EFAS dan matrik Internal Eksternal yang menurut posisi pemasaran QueCard Public Speaking adalah lembaga dapat memperluas pasar, mengembangkan produk lebih variatif, memperluas wilayah pasar, serta meningkatkan jumlah peserta. 
Program pemasaran yaitu program yang dapat diwujudkan oleh lembaga agar tujuan pemasaran dapat tercapai. Program pemasaran dirancang dari hasil strategi pemasaran yang ada pada analisis SWOT.

\section{Kesimpulan}

Peluang, ancaman, kelemahan dan kekuatan pemasaran QueCard Public Speaking dianalisa dengan scanning lingkungan internal dan eksternal yang akan diproyeksikan menjadi matriks EFAS dan IFAS. QueCard Public Speaking banyak peluang jika diambil dari berbagai data yang sudah dikumpulkan, antara lain dengan wawancara yang dilakukan kepada owner, stake holder, serta peserta pelatihan. Peluang yang dapat diteliti adalah jumlah masyarakat di pasar sasaran yang besar, lokasi yang strategis serta belum adanya pesaing pada lembaga pelatihan serupa. Ancamannya adalah sulitnya mencari mentor baru yang berkualitas, serta kurangnya pengetahuan masyarakat tentang ilmu komunikasi khusunya public speaking. Kekuatan yang diteliti pada pelatihan QueCard Public Speaking adalah kondisi kelas yang nyamah, materi yang sesuai serta biaya yang terjangkau, dan kelemahannya adalah promosi belum dilakukan secara maksimal.

\section{Referensi}

Adha, Kholifatul, 2014, Panduan Mudah Public Speaking, Notebook, Jakarta.

Arwana et al., 2017. Minapolitan Area Development Strategy: An Effort to Increase Fisherman Income, Gianyar Regency, Bali Indonesia. International Journal of Life Sciences, 2(1), p. 39-47.

Buchari, Alma, 2013, Manajemen Pemasaran dan Pemasaran Jasa, CV. Alfabeta, Bandung.

David, Fred R, 2009, Manajemen Strategi Konsep, Salemba Empat, Jakarta.

Freddy Rangkuti, 2009, Strategi Promosi yang Kreatif dan Analisis. Kasus. Intregrated Marketing Communication, PT. Gramedia Pustaka Utama, Jakarta. Heene, A \& Desmidt, S. 2010, Manajemen Strategik Keorganisasian, PT. Refika
Aditama, Jakarfta.

Hojanto, Ongky, 2012, Public Speaking Mastery, Gramedia, Jakarta.

Hurriyati, Ratih, 2010, Bauran Pemasaran dan Loyalitas Konsumen, Alfabeta, Bandung.

Kotler, Philip and Gary Amstrong. 2012, Prinsip-prinsip Pemasaran Edisi 13 Jilid 1, Jakarta, Erlangga.

R, Lita., 2010. Pengaruh Implementasi bauran Pemasaran Jasa Terhadap Proses keputusan Wisatawan mengunjungi Objek Wisata Di Kota Padang, Jurnal Manajemen Pemasaran Modern, 2(2), p. 91-99.

Sugiyono, 2010, Metode Penelitian Pendidikan, Alfabeta, Bandung. Tjiptono, Fandy. 2010, Strategi Pemasaran Edisi 2, Andi Offset, Yogyakarta.

Wahyuni, Endang., 2015. Hubungan SelfEffecacy dan Keterampilan Komunikasi dengan Kecemasan Berbicara di Depan Umum, Jurnal Komunikasi Islam , 05 (01), p. 51-82. 